\title{
ARÍBALOS DEL PERÍODO TARDÍO (1400-1536 DC) EN EL NORTE DE CHILE. SOPORTES SEMÁNTICOS E IDENTIDAD EN EL TAWANTINSUYU
}

\author{
LATE PERIOD (1400-1536 AD) ARYBALLOS IN NORTHERN CHILE. \\ SEMANTIC MEDIA AND IDENTITY IN THE TAWANTINSUYU
}

Freddy Viñalesa, Claudia Ogalde ${ }^{B}$, Juan Pablo Ogalde ${ }^{C} \&$ Bernardo Arriaza ${ }^{D}$

Se presentan los resultados del estudio orientado a entender el rol social del aríbalo en el norte de Chile durante el Tawantinsuyu o Período Tardío (1400-1536 DC). En la decoración de algunos de estos objetos se observa iconografía aymara, y a su vez, las distintas especies vegetales contenidas (maíz, frijol, yuca, pallar) podrían estar relacionadas con ritos fúnebres propios del Collasuyu. En resumen, la circulación de formas con influencia Inca (i.e. el aríbalo), a través de los ritos funerarios locales, permite entender la identidad del sujeto en el contexto fúnebre.

Palabras clave: Aríbalo, Horizonte Inca, Período Tardío, Arica, Altiplano, Cementerio.

In this work we discuss the social role of the aryballos in northern Chile during the Tawantinsuyu or Late Period (1400-1536 AD). Additionally, the decoration of some of these objects shows Aymara iconographic motifs, while the different plant species kept in these vases (corn, beans, yucca, Lima bean) could be related to Collasuyu funeral rites. In summary, the circulation of forms with Inca influence (i.e. aryballos), mediated with local funeral rites, allowed for the negotiation of the identity of the subject in the funeral context.

Keywords: Aryballos, Inca Horizon, Late Period, Arica, High plateau, Graveyard.

\section{INTRODUCCIÓN}

El Estado inca extendió sus fronteras hacia una importante área de los Andes a lo largo del Período Tardío u Horizonte Inca (1400-1536 DC). Este territorio denominado Tawantinsuyu tuvo su capital en Cusco y estuvo políticamente dividido en cuatro grandes regiones o suyus: Chinchaysuyu hacia el norte, Contisuyu al oeste, Collasuyu hacia el sur y Antisuyu al este (Rowe 1944, Murra 1978, Pärssinen 2002, Rostworowski 2014).

Uno de los mecanismos con que el Inca materializó la ideología del imperio en las áreas bajo su dominio, fue la producción de un juego de vajilla estatal ampliamente difundido en estos territorios (Bray 2004). La vajilla ha sido definida como un conjunto estandarizado de formas cerámicas, tales como escudillas, queros, aríbalos, ollas y otras vasijas (Rowe 1961, Meyers 1975), configurando una materialidad capaz de exaltar la jerarquización social y espacial del Tawantinsuyu (D’Altroy et al. 1994, Morris 1995, Bray 2003a, Dillehay 2003).

\footnotetext{
A Freddy Viñales, Universidad Católica del Norte, Instituto de Arqueología y Antropología (IAA), Gustavo Le Peige 380, 1410000, San Pedro de Atacama Chile. E-mail: freddy.vinales@gmail.com

B Claudia Ogalde, Programa de posgrado en Antropología, UCN-UTA, Universidad de Tarapacá, Arica, Chile. E-mail: c.ogaldeherrera@gmail.com

C Juan Pablo Ogalde, Instituto de Alta Investigación, Universidad de Tarapacá. E-mail: jpabloogalde@yahoo.es

D Bernardo Arriaza, Instituto de Alta Investigación, Universidad de Tarapacá. E-mail: barriazaarica@gmail.com
} 
En particular, se destaca la parafernalia material que en el Tawantinsuyu estuvo asociada a importantes protocolos de convite en las libaciones estatales (Randall 1993, Dillehay 2003, Cummins 2004, Arriaza et al. 2016). Prácticas conocidas como políticas del comensalismo (Dietler 2006) se habrían realizado ininterrumpidamente en el caso de los Andes desde tiempos tempranos hasta el Inca (Bray 2003b, Goldstein 2003), impulsando la creación de un conjunto especializado de vajilla elaborada en metal, cerámica y madera, diseñada para fabricar, transportar y consumir chicha de maíz u otras bebidas (Bray 2003a, 2004, Cummins 2004). Este tipo de vajilla se definió como Inca Cusqueño y sus variaciones provinciales como Inca Local o Altiplánica (Rowe 1944, 1961, Meyers 1975), las cuales habrían sido utilizadas como tecnologías de poder al servicio de la expansión inca (D’Altroy et al. 1994, Hayashida 1998, Bray 2003b, Dillehay 2003).

Bray (2004) realizó un estudio de la distribución de la vajilla Inca a partir del análisis de más de 2000 artefactos provenientes del Cusco y otras áreas provinciales. Concluyó que el aríbalo es la forma más común en la muestra ( $\mathrm{N}=1200)$, seguido de las escudillas $(\mathrm{N}=611)$. Junto con esto, se determinó que, no obstante el número de aríbalos registrados en el centro es abundante (37\%), este aumenta en las provincias del Tawantisuyu (44\%). Por lo tanto, su distribución es mayor en áreas periféricas, mientras que en el Cusco predomina la presencia de grandes aríbalos y tinajones, utilizados probablemente para cocinar abundantes cantidades de chicha (Bray 2003b, Hayashida 2008). A partir de las reflexiones de Bray $(2004,2009)$, creemos que el aríbalo sería el artefacto -relativo a la libación con chicha de maíz- que mejor representa y describe las dinámicas políticas y económicas de la fase expansiva del Estado inca (fig. 1).

En el ámbito local, la libación ritual de chicha en aríbalos también se incluía en algunos actos estatales, como las inmolaciones humanas -denominadas capacochas-, que conllevaban el reconocimiento oficial de un grupo étnico local preponderante (Besom 2013, Rostworowski 2014). Las capacochas del volcán Llullaillaco en el Noroeste Argentino, las del cerro El Plomo en Chile central o el entierro Inca de élite del cerro Esmeralda en Iquique (Checura 1977; Besom 2000, 2013; Ceruti 2003, Reinhard \& Ceruti 2005; Arriaza et al. 2016, 2018, entre otros) son evidencias de que, en esta macroárea denominada Collasuyu, el Estado inca reconoció unidades políticas importantes y negoció con ellas.

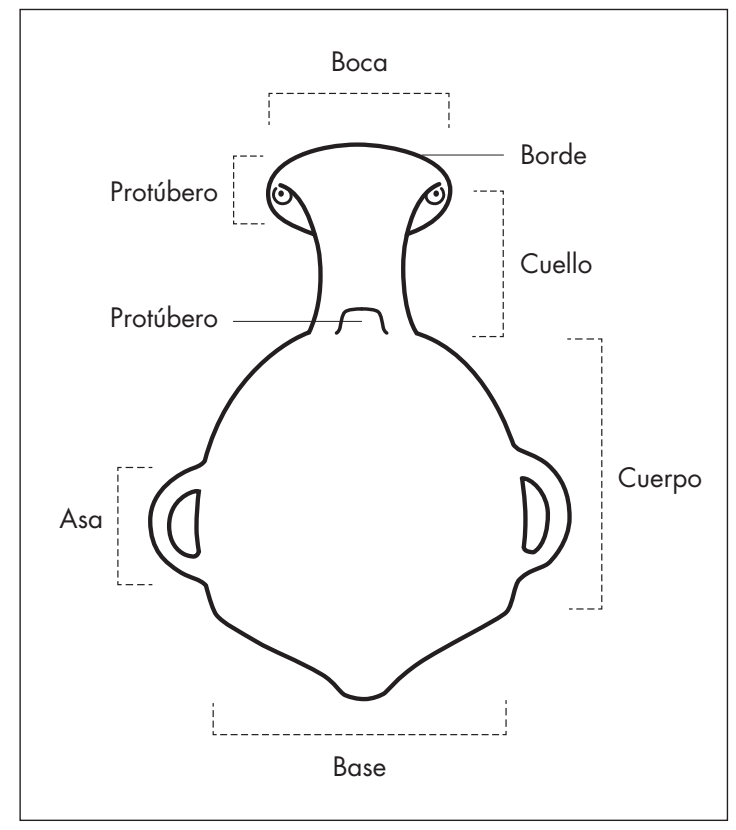

Figura 1. Segmentos y atributos morfológicos del aríbalo. (Dibujo: gentileza de N. Cisterna). Figure 1. Segments and morphological features of the aryballos (Drawing: courtesy of N. Cisterna).

A partir de estos antecedentes, nos hemos planteado como problema conocer cuál fue la función de los aríbalos hallados en los valles occidentales y en la costa de la actual Región de Arica y Parinacota del norte de Chile, en los eventos sociales del Horizonte Inca, centrándonos en su morfología, decoración y contenido. El aríbalo parece ser un caso privilegiado para la difusión y asimilación de formas tecnológicas del Estado inca en sus áreas periféricas (fig. 2).

\section{ARTEFACTOS, PRÁCTICAS FÚNEBRES Y LA IDENTIDAD}

Hemos puesto el foco en la capacidad de "agencia que tienen las cosas" (Ingold 2008, Latour 2008, Gell 2016), para estudiar los artefactos como soporte de las relaciones entre tecnología y sociedad. Esta característica nos remite a una categoría que explicita la influencia de las cosas en la conducta de una persona, incluso en contra de su propia voluntad. Por agencia entendemos, entonces, las extensiones del poder a través de las cosas. Su aplicación en arqueología (i.e. Smith 2001, Silliman 2001, Robb 2008, 2010, Sillar 2009) permite dar un 
giro analítico hacia la particularidad y subjetividad del proceso tecnológico.

El aríbalo es un prototipo que soporta información significativa, sustancia misma de su agencia. Por lo tanto, este estudio aborda la capacidad de agencia del aríbalo como estilo tecnológico, considerando que el diseño es el resultado de la tensión entre productores y usuarios (Thomas \& Buch 2013). El alcance descriptivo de un estilo tecnológico surge de la relación entre los patrones factuales y semánticos, los que se constituyen como rasgos estables en la tecnología arqueológica (Lechtman 1977, Dobres 2010, Martinon-Torres \& Killick 2016). A partir de esto, es interesante evaluar los elementos simbólicos de este artefacto en las áreas periféricas al Tawanatinsuyu. Así, la dinámica de la proliferación del aríbalo podría remitir a aquellos procedimientos mediante los cuales los grupos que detentan el poder se articulan con la sociedad determinando "regímenes de verdad" (Foucault 2010); vale decir, se trataría de un artefacto con un alto valor simbólico y político, que se resuelve en pro del Estado inca. En otras palabras, el aríbalo formaría parte del sentido común generalizado de las personas, ya que sería relativo al orden del mundo o a ideologías en las que son naturalizadas las posiciones subordinadas de los sujetos y las cosas.

En cualquier caso, destacamos la fuerte carga semántica unida a las tecnologías de gobierno (Rosberry 2002, Han 2019), como podría ser el caso del aríbalo. Esto quiere decir que, por medio de la producción de soportes semánticos, el poder se inscribe en un horizonte orientado a interpelar directamente la identidad de los sujetos, vinculándolo al campo de acción de un determinado régimen de gobierno (Althusser 1988, Foucault 2010, Li 2000).

$\mathrm{Al}$ asumir la agencia de los objetos, nuestro examen los caracteriza como articuladores entre las fuentes del poder y los sujetos. Este prisma reconoce, por consiguiente, la situacionalidad política -por lo tanto, también semiótica- implicada en toda forma tecnológica (Winner 1977, Haraway 1991, Latour 1999, Han 2019) y con ello las posibilidades de articular identidades a un proceso tecnológico particular (Hall 1995, Li 2000, Agrawal 2005).

Los aríbalos del norte de Chile estudiados son parte del ajuar fúnebre y es en este escenario funerario donde se va a resolver fuertemente la identidad social del sujeto, puesto que es un espacio no cotidiano, de profunda transcendencia escatológica y que permite a los deudos mostrar quién era su muerto (Van den Berg 1989, Albó 1991, Van Kessel 1999). Este rico escenario emocional y cognitivo facilita el despliegue de un proceso respecto de su identidad y con múltiples niveles de significación, pues es un evento que propicia la reflexión temporal y una declaración de otredad (Villanueva 2014, Amuedo 2015). Así, finalmente, el estudio del aspecto simbólico del aríbalo permitirá -por abducción- inferir parte importante de la identidad del sujeto al que acompaña en su ajuar fúnebre.

\section{MUESTRA Y MÉTODO}

\section{Muestra}

La muestra de estudio corresponde a 29 aríbalos de los siguientes sitios: Lluta 13 (LLU 13), Lluta 54 (LLU 54), Azapa 15 (Az 15), Playa Miller 4 (PLM 4), Playa Miller 6 (PLM 6) y Chaca 5, provenientes de la costa de Arica y de los valles de Azapa, Chaca y Lluta. Estos artefactos se conservan en el Museo Arqueológico San Miguel de Azapa (MASMA), perteneciente a la Universidad de Tarapacá. Se utilizó un grupo de control que incluye algunos casos de Patillo y Cerro Esmeralda, del Museo Regional de Iquique (MRI); y otro grupo de piezas cerámicas lo constituyen algunos casos de aríbalos del poblado de Caspana (CAs 1), resguardadas en el Depósito Arqueológico de la Corporación de Cultura y Turismo de Calama (fig. 2). Del total responderían a aríbalos, tres ejemplares de aríbalos miniaturas y nueve jarras globulares con algún atributo morfológico similar a los del aríbalo (tabla 1).

\section{Método}

Los métodos utilizados para el análisis semántico del aríbalo incluyeron la revisión de colecciones y muestreo, análisis métrico y morfológico, decorativo, de uso y estado de conservación y, por último, la alfarería experimental.

\section{Revisión de colecciones}

Se revisaron las colecciones de más de 150 contextos fúnebres de los cementerios Lluta 13 (LLU 13), Lluta 54 (Llu 54), Azapa 15 (Az 15), Playa Miller 4 (PLM 4), Playa Miller 6 ( (plm 6), Chaca 5 y Camarones 9. Estos sitios arqueológicos presentan contextos fúnebres de los 
Períodos Intermedio Tardío (1000-1400 DC) y Tardío (1400-1532 DC). Esta revisión consideró la selección de contextos para análisis métricos, teniendo como criterio la presencia de vasijas para contener líquido en el ajuar fúnebre.

\section{Análisis métrico}

Para las vasijas seleccionadas se utilizaron los siguientes criterios métricos: alto máximo con y sin ícono, ancho máximo, largo y ancho del cuello, largo y ancho de las asas, ancho de boca interna y ancho de la base. Como se observa, se tuvo especial cuidado con la métrica en cuerpo, base, cuello y asas por ser componentes elementales de una vasija. Luego, sobre la base de la morfología se elaboró una tipología de los aríbalos del norte de Chile.

\section{Análisis decorativo}

Seguidamente, se determinó una subcategorización de acuerdo con la presencia o ausencia de iconografía y determinados atributos secundarios o adornos. En particular, los aspectos formales de la decoración se estudiaron en tres niveles. El primero es el preiconográfico, cuyo contenido asocia formas visuales con representaciones de objetos naturales (Panofsky 2004: 14-15). El segundo es el análisis iconográfico que determina el significado mediante la asociación de las formas o imágenes, lo que conlleva a la materialización de temas o conceptos (Panofsky 2004: 16). El último nivel es la interpretación iconológica, que busca ahondar en el significado intrínseco o contenido simbólico del conjunto icónico (Panofsky 2004: 17).

\section{Análisis de uso y estado de conservación}

Definir el uso de los artefactos es complejo, pues no está bien delimitado el momento exacto en que se dejaron de utilizar. De acuerdo con la hipótesis de este trabajo, los aspectos necesarios de evaluar son: el contexto arqueológico del hallazgo, las evidencias y marcas de uso, y el análisis microbotánico de su contenido.

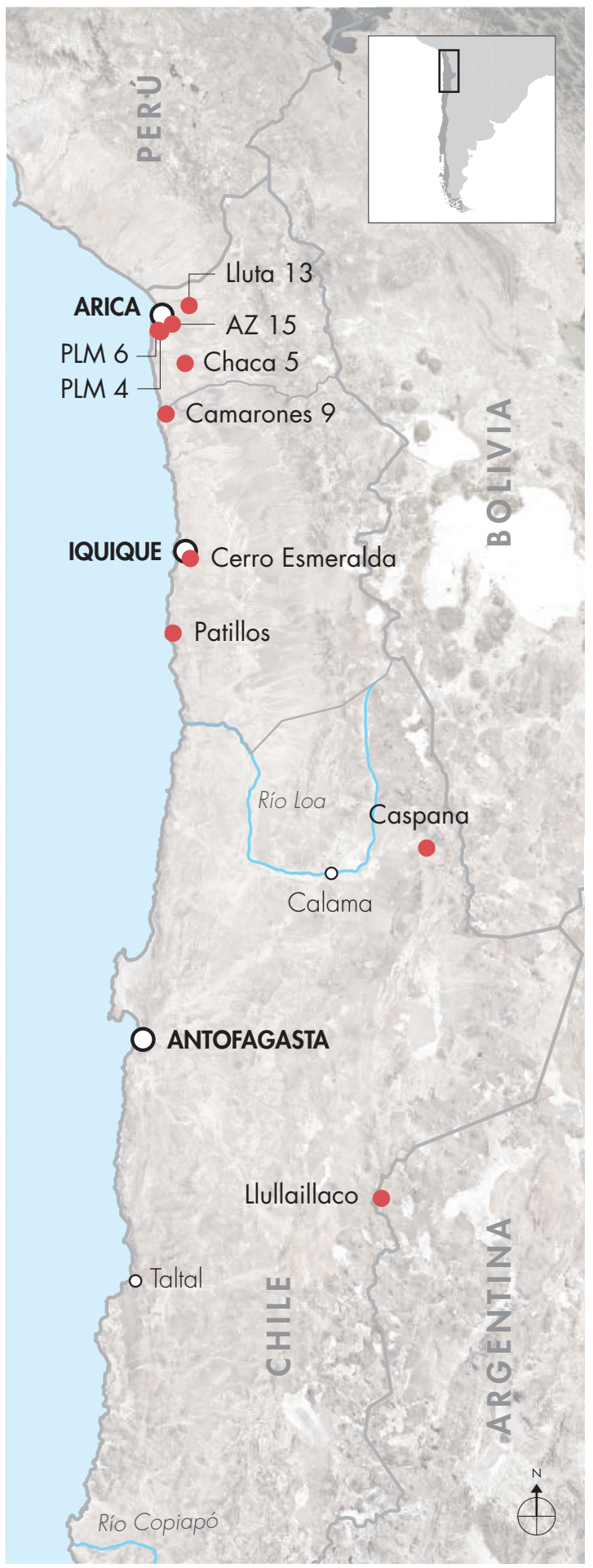

Figura 2. Sitios de la muestra de aríbalos. Figure 2. Sites of provenance of the aryballos sample. 
Tabla 1. Muestra de aríbalos analizada. Table 1. Aryballos sample analyzed.

\begin{tabular}{|c|c|c|c|c|c|c|c|}
\hline SITIO & TUMBA & ID MUESTRA & $\begin{array}{l}\text { PROTÚBEROS } \\
\text { TIPO OREJAS }\end{array}$ & $\begin{array}{l}\text { PROTÚBERO } \\
\text { EN CUERPO }\end{array}$ & $\begin{array}{l}\text { PRESENCIA } \\
\text { DE ASAS }\end{array}$ & DECORACIÓN & TIPO \\
\hline LLU 54 & 20 & 122 & Ausentes & No & Sí & No & E \\
\hline LLU 54 & 34 & 259 & No & No & Sí & No & $\mathrm{E}$ \\
\hline LLU 13 & c3-1 & 3108 & Sí & Sí & Sí & Sí & B \\
\hline $\mathrm{Az} 15$ & $\mathrm{~S} / \mathrm{T}$ & 2598 & Sí & Sí & Sí & Sí & A \\
\hline Az 15 & $\mathrm{~S} / \mathrm{T}$ & 30370 & Sí & Sí & Sí & Sí & B \\
\hline $\mathrm{Az} 15$ & 26 & 1598 & Ausentes & Sí & Sí & Sí & B \\
\hline $\mathrm{Az} 15$ & 29 & 2630 & Sí & Sí & Sí & Sí & B \\
\hline $\mathrm{Az} 15$ & 40 & 21866 & Ausentes & Sí & Ausentes & Sí & B \\
\hline Az 15 & 52 & 2900 & Ausentes & Sí & Sí & Sí & B \\
\hline $\mathrm{Az} 15$ & 59 & 2978 & Sí & Sí & Sí & Sí & B \\
\hline $\mathrm{Az} 15$ & 98 & 5129 & Ausentes & Sí & Sí & Sí & B \\
\hline Az 15 & $\mathrm{~S} / \mathrm{T}$ & 27265 & Sí & Sí & Sí & Sí & B \\
\hline PLM 4 & 106 & 8765 & Sí & Sí & Sí & Sí & B \\
\hline PLM 4 & 109 & 8809 & Sí & Sí & Sí & Ausente & B \\
\hline PLM 4 & 99 & 8607 & Ausentes & Sí & Sí & No & $\mathrm{C}$ \\
\hline PLM 4 & 83 & 8215 & Sí & Sí & Ausentes & No & $\mathrm{E}$ \\
\hline PLM 6 & 14 & 3436 & Ausentes & Sí & Sí & Sí & B \\
\hline PLM 6 & 15 & 3448,1 & Ausentes & Sí & Sí & Sí & B \\
\hline PLM 6 & 15 & 3448 & Sí & Sí & Sí & Sí & B \\
\hline Chaca 5 & 25 & 1221,1 & Sí & Sí & Sí & Sí & $\mathrm{C}$ \\
\hline Chaca 5 & 35 & 1222 & No & No & Sí & No & $\mathrm{D}$ \\
\hline Cerro Esmeralda & Capacocha & Caja 7-MRI0010 & Sí & Sí & Sí & No & A \\
\hline Patillos & $\mathrm{S} / \mathrm{T}$ & 1762 & No & No & Sí & No & $\mathrm{D}$ \\
\hline CAS 1 & 61 & В 233 & No & No & Sí & No & $\mathrm{D}$ \\
\hline
\end{tabular}

\section{Alfarería experimental}

Después del análisis formal, se reprodujeron una serie de aríbalos en el Taller de Cerámica Artística de la Universidad de Tarapacá, lo que permitió una aproximación experimental al ensamblaje del aríbalo en condiciones ideales de manufacturación.

\section{RESULTADOS}

Los análisis efectuados sobre las piezas arqueológicas permitieron identificar tres partes estructurales del aríbalo que se fabrican de forma separada: el cuello, hiperboloide o recto con borde horizontal, el cuerpo, elipsoide o esférico, y la base, cónica o redondeada. En 


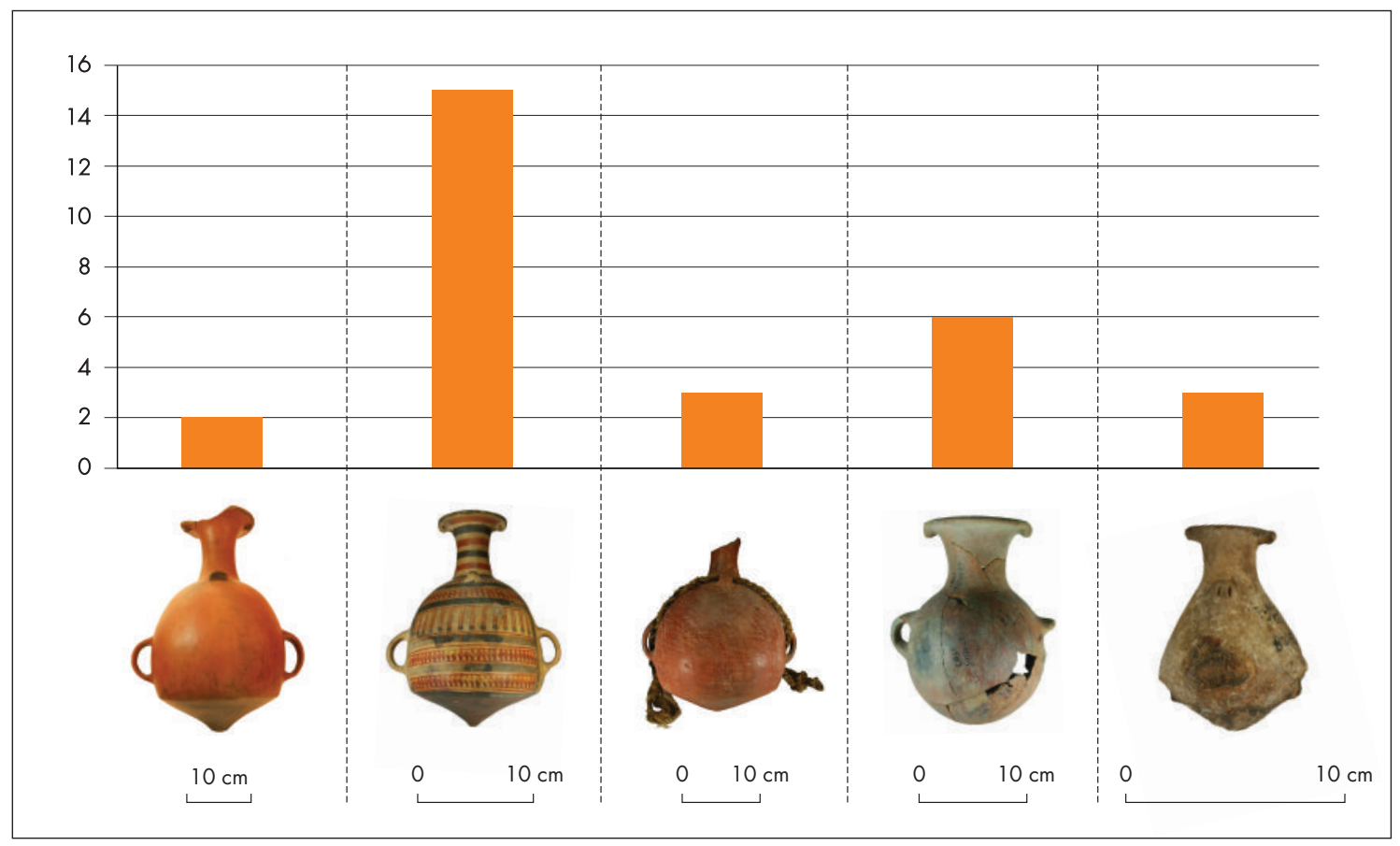

Figura 3. Tipología y frecuencia de las piezas analizadas. Figure 3. Typology and frequency of pieces analyzed.

general, se debe procurar un secado homogéneo entre las partes y a la sombra para evitar fisuras, lo que podría extenderse por cerca de una semana. Posteriormente, se ensamblan los segmentos formando la matriz sobre la que se adhieren otros atributos funcionales y ornamentales, como los protúberos.

La construcción de cada pieza completa puede demorar varios días, en una serie de eventos separados según la especificidad técnica de cada parte. Una vez ensamblado el aríbalo, y luego de que la pieza está completamente seca, se trabaja en su superficie (alisado, bruñido, etc.), para finalizar con el cocido y decoración del material. Después del decorado se vuelve a cocer para fijar el pigmento.

El principal rasgo morfológico que determina diferencias entre los ejemplares estudiados son los ángulos de unión entre cada parte: superior (cuello), medio (cuerpo) e inferior (base). A partir del agrupamiento y estudio métrico, morfológico y decorativo de estas subestructuras, se establecieron aquellas diferencias (aunque mínimas) que permitieron agrupar las piezas analizadas en cinco tipos morfofuncionales: Grupo A (2 piezas), Grupo B (15 piezas), Grupo C (3 piezas), Grupo D (6 piezas), Grupo E (3 piezas) (fig. 3 ) (tabla 2 ).
Tabla 2. Tipología y distribución de aríbalos por sitio. Table 2. Typology and distribution of aryballos per site.

\begin{tabular}{l|c|c|c|c|c|c}
\multirow{2}{*}{ SITIO } & \multicolumn{5}{c|}{ TIPO } & \multirow{2}{*}{ TOTAL } \\
\cline { 2 - 6 } LLUTA 54 & A & B & C & D & E & \\
\hline LLUTA 13 & - & - & - & - & 2 & 2 \\
\hline AZAPA 15 & - & 1 & - & - & - & 1 \\
\hline PLAYA MILLER 4 & - & 2 & 1 & - & 1 & 4 \\
\hline PLAYA MILLER 6 & - & 3 & - & - & - & 3 \\
\hline CHACA 5 & - & - & 1 & 1 & - & 2 \\
\hline CERRO ESMERALDA & 1 & - & - & - & - & 1 \\
\hline PATILLOS & - & - & - & 1 & - & 1 \\
\hline CASPANA 1 & - & - & - & 4 & - & 4 \\
\hline NO REGISTRA & - & 1 & - & - & - & 1 \\
\hline TOTAL & 2 & 15 & 2 & 6 & 3 & 28 \\
\hline
\end{tabular}




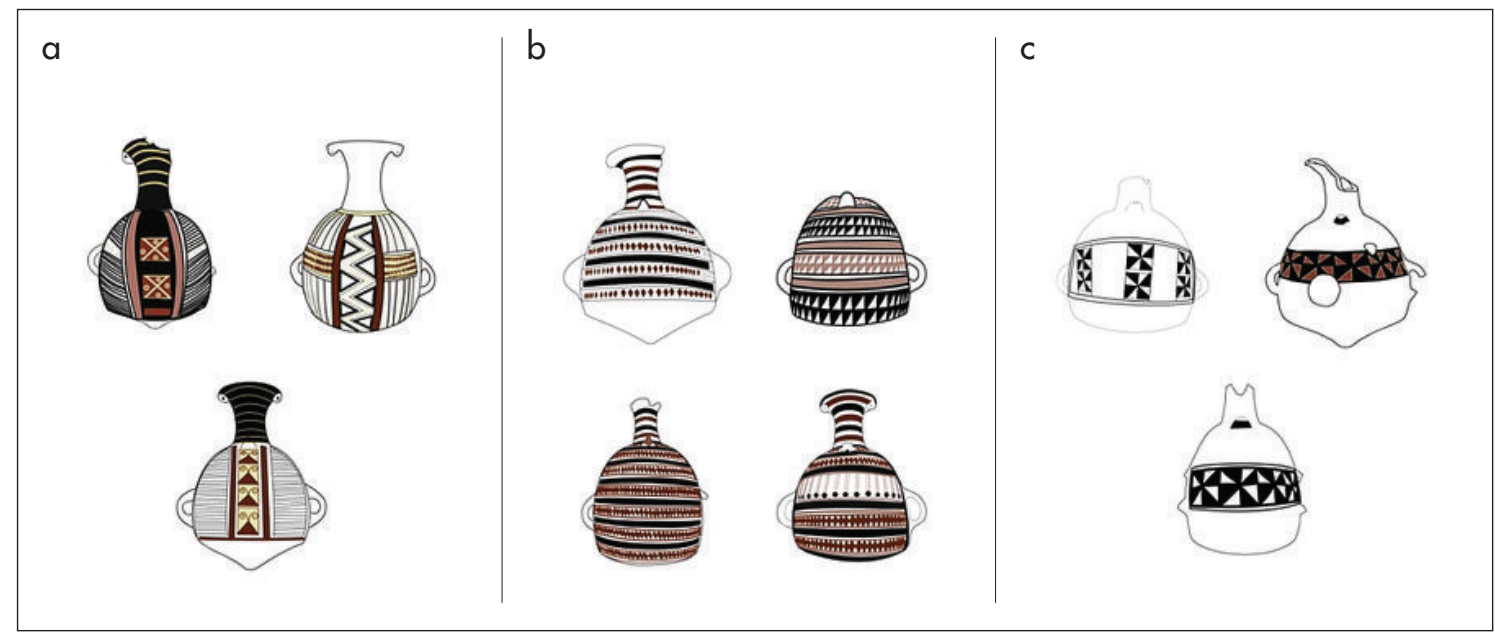

Figura 4. Patrones decorativos: a) estética de líneas verticales; b) estética de líneas horizontales; y c) estética de franjas de aspas. (Dibujos: gentileza de N. Cisterna). Figure 4. Decorative patterns: a) vertical lines stylistic mode; $\boldsymbol{b}$ ) horizontal lines stylistic mode; and c) blade stripe stylistic mode. (Drawings: courtesy of N. Cisterna)

Grupo A. Cuello hiperboloide con borde horizontal, cuerpo elipsoide restricto con un par de asas y base cónica, además, dos protúberos adosados al labio de la vasija y un tercero en el tercio superior del cuerpo. Estos aríbalos son los ejemplares de mayores dimensiones, con una altura máxima promedio de $40 \mathrm{~cm}$ y un ancho de casi $25 \mathrm{~cm}$ aproximadamente. La superficie se encuentra alisada y bruñida, engobada en rojo y sin motivos iconográficos. Se registraron dos casos, uno proveniente de Az 15 (recinto doméstico) y el otro de la capacocha de Cerro Esmeralda en Iquique.

Grupo B. Presenta atributos morfológicos análogos al grupo A, pero con una variación en el tamaño, siendo la altura máxima promedio de $19 \mathrm{~cm}$ y un ancho aproximado de $12 \mathrm{~cm}$. La superficie se encuentra alisada y en algunos casos bruñida; la mayoría de los ejemplares presentan un engobe rojo con motivos policromos en negro, blanco y amarillo (diferencia importante respecto del grupo A). En total se registraron 15 ejemplares: 8 de Az 15, 3 de PLM 6, 2 de PlM 4 y 1 de llu 13; se registró, además, otro ejemplar asociado al área de Arica, pero sin referencia del sitio.

Grupo C. Este grupo presenta el cuello hiperboloide con borde probablemente recto, el cuerpo redondo (atributo característico de este grupo), base cónica, un par de asas y protúberos, además de estar engobados. La altura máxima promedia los $21 \mathrm{~cm}$ y el ancho $22 \mathrm{~cm}$ aproximadamente. Se registraron 2 ejemplares, uno del sitio Chaca 5 (tumba 25) y otro de PLM 4 (tumba 99).
Grupo D. En general, este grupo es diferente a los demás y corresponde a jarras aribaloides que presentan indistintamente algún atributo de los aríbalos (i.e. cuello alargado, par de asas, base cónica, protúberos), pero ningún ejemplar incluye iconografía. El cuello es hiperboloide y en un caso, recto. El cuerpo tiende a ser elipsoide y de base cónica, aunque las piezas difieren entre sí, con una altura máxima promedio de $10 \mathrm{~cm}$ y un ancho de $11 \mathrm{~cm}$ aproximadamente. Se registraron 6 ejemplares provenientes de los sitios Chaca 5 en Arica, Patillos de Iquique y del cementerio Caspana 1 en el Loa.

Grupo E. Corresponde a aríbalos que siguen el prototipo del Grupo A, aunque de pequeñas dimensiones y sin iconografía, con un alto máximo promedio de 10 $\mathrm{cm}$ y un ancho de $8 \mathrm{~cm}$ aproximadamente, sin decoración. Una pieza presenta el cuello recto. A diferencia de los grupos anteriores, en estos se observa menor acabado técnico.

En términos del análisis iconográfico, la presencia de decoración es un atributo importante para segregar al Grupo B, mientras que, al menos un caso del grupo C, muestra decoración. Para efectos de los objetivos propuestos en este estudio, se han agrupado en tres los conjuntos decorativos, según: a) estética de líneas verticales, b) estética de líneas horizontales y c) estética de franjas de aspas (fig. 4).

Estética de líneas verticales. En general, esta decoración cubre la mitad frontal del cuerpo y en algunos 
casos el cuello. El panel iconográfico, que puede tener continuidad alrededor del cuerpo con líneas o aros en la parte superior del cuerpo, presenta una característica común: dos líneas verticales que dividen el campo iconográfico en tres, donde el subpanel principal es el del centro, mientras que los subpaneles laterales son especulares y simétricos.

Estética de líneas horizontales. Esta decoración cubre la mitad del cuerpo y el cuello, aunque hay piezas sin cuello por fractura, donde no ha sido posible evaluar la decoración. El panel iconográfico puede tener continuidad alrededor del cuerpo con líneas o aros en la parte superior del cuerpo. La característica común es una diagramación de líneas horizontales negras (y rojas en el cuello), con una secuencia de rombos rojos, triángulos negros y rojos intercalados y, ocasionalmente, (al menos una vez) el motivo de espigas (secuencia de dos líneas paralelas con un círculo distal).

Estética de franjas de aspas. Esta decoración cubre las áreas centrales de la mitad del cuerpo, presentando una o tres franjas verticales $\mathrm{u}$ horizontales con motivo de aspas de colores negro y blanco y, ocasionalmente, rojo.

Respecto del análisis microscópico del contenido, fueron analizados cuatro aríbalos, resultando tres casos positivos. El ejemplar de la tumba 59, sitio Az 15, perteneciente al Grupo B de iconografía horizontal, presentó granos de almidón de Zea mays (maíz), Phaseolus vulgaris (frejol), Phaseolus lunatus (pallar) y Pouteria lucuma (lúcuma). Otro aríbalo del área de Arica sin contexto arqueológico, también del grupo B con iconografía de líneas verticales, contenía almidón de maíz, frejol y Manihot esculenta (yuca). El tercer caso proviene del entierro Inca de élite en Cerro Esmeralda, con resultados muy similares, los que merecieron una publicación independiente (Arriaza et al. 2016).

\section{DISCUSIÓN}

Se puede argumentar que hay requerimientos corporales mínimos (gestualidad) para el uso del aríbalo. Elementos como el alineamiento de las asas y los protúberos son concordantes con el uso de sogas para transportarlos en la espalda (fig. 5f).

Asimismo, hay aspectos mecánicos fuertemente unidos a la estructura y función del aríbalo. Por ejemplo, la decantación progresiva del contenido fermentado también es favorecida con las subestructuras del cuello, cuerpo y base, mientras que la base cónica, que puede ser hundida en el suelo, permite una mayor estabilidad dinámica a este tipo de vasijas. El cuello del aríbalo podría facilitar la colocación de un tapón, como en el caso del aríbalo del Grupo E, tumba 54 de Lluta 54, que podría servir para conservar la bebida y también para regular la potencial fermentación, al aislar y dar una atmosfera reductora a la fermentación, obstaculizando el paso de oxígeno desde afuera y controlando la liberación de dióxido de carbono $\left(\mathrm{CO}_{2}\right)$. Además, sirve para una mejor distribución/servido del contenido. Por su parte, el cuerpo del aríbalo determina la capacidad volumétrica y de carga, lo cual afecta en el peso y la capacidad de su manipulación. Estos aríbalos presentan también detalles significativos, como los protúberos adosados al labio del aríbalo, que sirvieron para colgar ornamentos como plumas o hilos.

El conjunto de elementos materiales asociados a la forma del objeto es parte importante de la "idea de artefacto" que se materializa en el aríbalo, haya o no conciencia de esto en los artesanos que los fabricaron. La ideación tecnológica del aríbalo con el conjunto de elementos morfofuncionales descritos, conlleva significativas similitudes entre los prototipos de aríbalos que proliferaron en las áreas nucleares del Tawantinsuyu y las piezas estudiadas del Grupo A y B. También se observan adaptaciones locales de ideas morfofuncionales relativas a contenedores de chicha para servir, como las jarras estudiadas de Caspana correspondientes al Grupo D, las que provienen del área atacameña, además de otros grupos donde el elemento lúdico pudiese estar (omni-) presente (Grupo E).

Así, los referentes de los Grupos A y B estarían en las áreas nucleares del Tawantinsuyu, asociados a contextos de gran complejidad política y estatal, tales como recintos principales, santuarios de altura y el mismo Cusco (Rowe 1961, Checura 1977, Ceruti 2003). Estos grupos muestran artefactos que proliferan a propósito del Estado inca con determinadas dimensiones en áreas periféricas, en contraposición de otros artefactos que materializan las ideas morfofuncionales (prototipos) de los aríbalos adaptándolos a las tradiciones locales de hacer jarras (Grupo D).

En Arica, el Grupo A aparece asociado al único recinto habitacional de piedra de la época en el sitio Az 15 (Santoro y Muñoz 1981, Focacci 1981), que presenta un patrón constructivo Inca (Piazza 1981). Otro ejemplar forma parte del ajuar fúnebre de entierro 
a

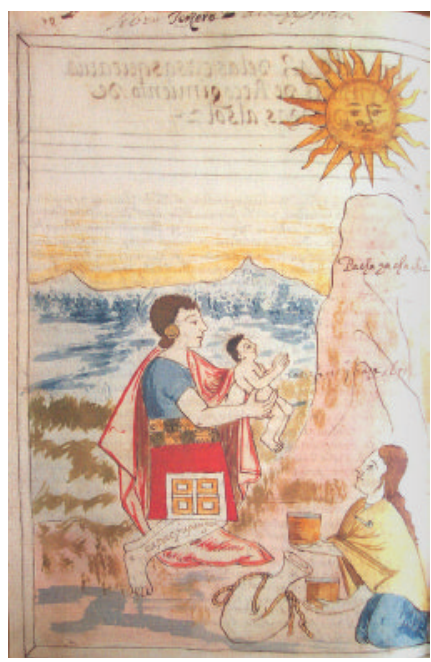

d

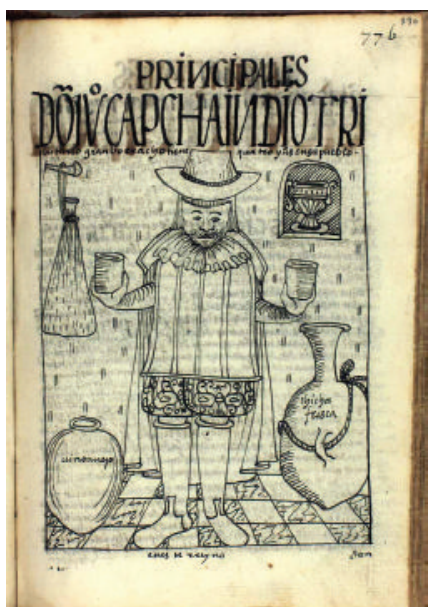

b

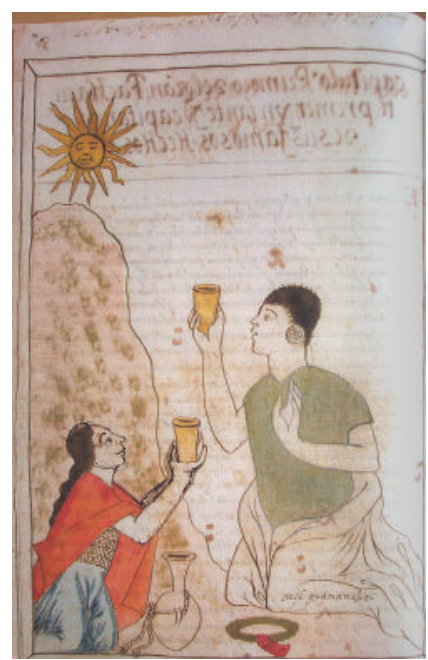

e

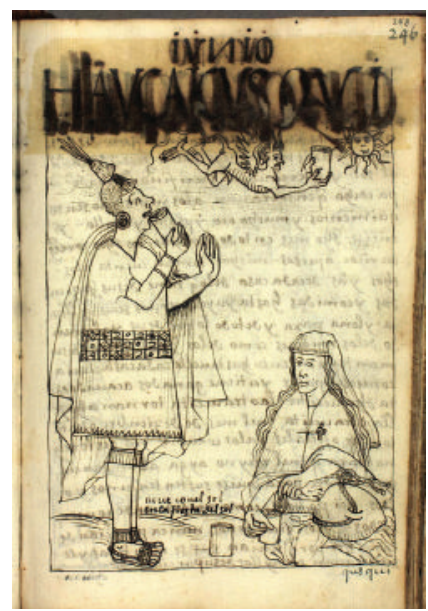

C

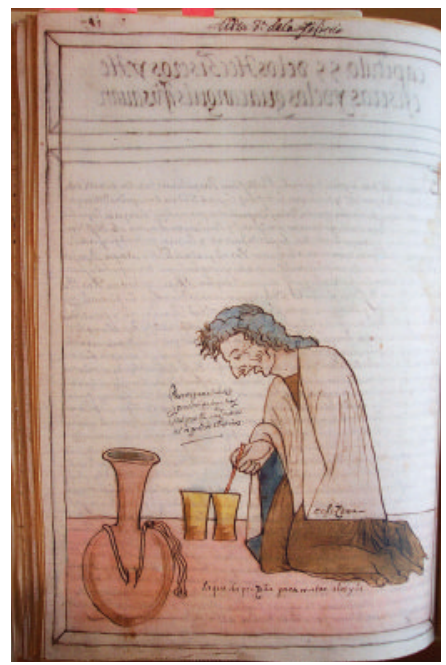

f

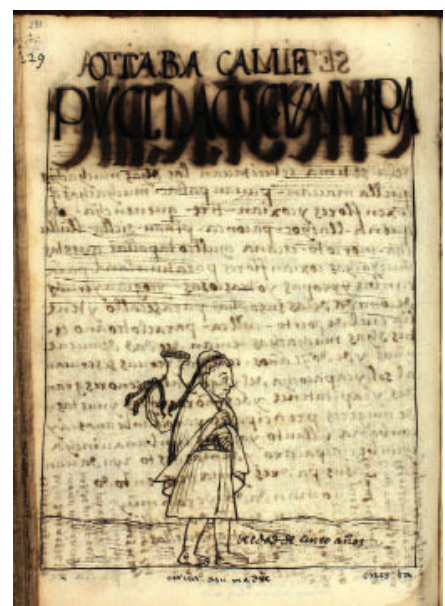

Figura 5. Usos y significados del beber. (Dibujos: a, b y c extraídos de ms. Galvin 1590; d y e extraídos de Guaman Poma de Ayala 1615; fotografía f: extraída de Cummins 2004). Figure 5. Use and meanings of drinking. (Drawings: $a, b$ and $c$ taken from Galvin 1590; $d$ and $e$ taken from Guaman Poma de Ayala 1615; Photograph f: taken from Cummins 2004).

Inca de élite de Cerro Esmeralda en Iquique (Arriaza et al. 2016, 2018, Checura 1977). En tanto, el Grupo B se corresponde mayormente con los aríbalos que estudia Bray (2003a, 2004, 2009), denominados medianos, los que tienen mayor difusión en áreas periféricas al Tawantinsuyu.
Esta contraposición de elementos culturales foráneos y locales en la forma de las vasijas se observa también en la decoración. Al respecto, se pudo determinar la recurrencia de tres patrones decorativos, Grupos I, II y III, predominando el patrón de diseño de aspas (fig. 4, Grupo III). Este tipo de diseño iconográfico ha sido 


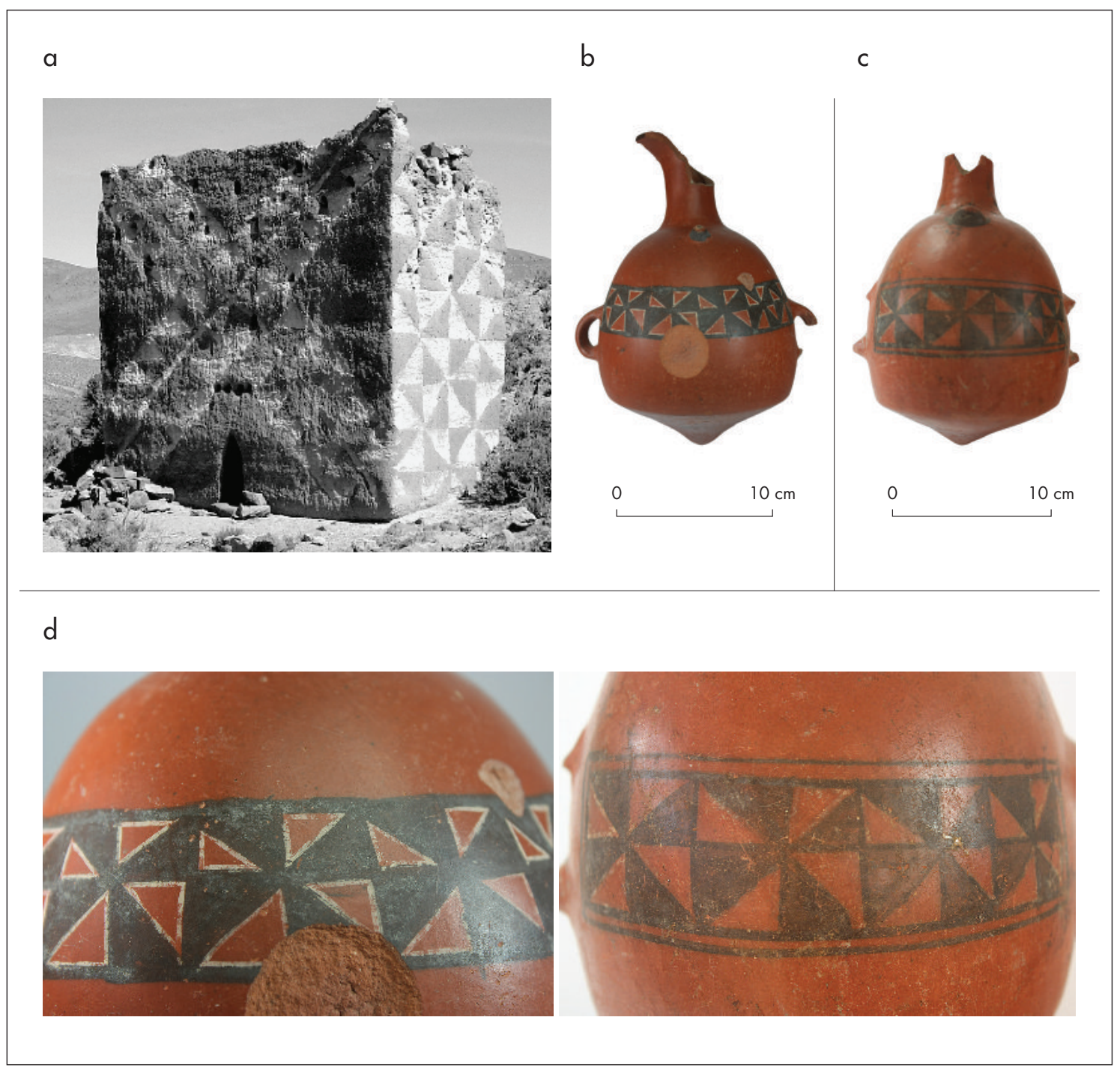

Figura 6: a) chullpa decorada con diseño en aspas del sitio Willa-Kollu, área Carangas; b) aríbalo del sitio Playa Miller 6, tumba 14, n 3436; c) aríbalo del sitio Lluta 13, n 3108 (Núñez et al. 1994: 96); d) diseño en aspas. Figure 6: a) Chullpa (funerary tower) with blade design from Willa-Kollu site, Carangas area; b) aryballos from Playa Miller site, grave 4, n 3436; c) aryballos from Lluta 13 site, n 3108 (Núñez et al. 1994: 96); d) blade design.

asociado a chullpas del sector Carangas del altiplano boliviano con motivos similares en su decoración (fig. 6a) (Kesseli \& Pärssinen 2005, Taboada et al. 2013, Horta 2015).

El Grupo II tiene intercalado ocasionalmente el motivo de "espiga". Este aparece reiteradamente en aríbalos y jarras denominadas aisana utilizadas en el entierro Inca de élite en Cerro Esmeralda en Iquique y en la capacocha de Llullaillaco, Noroeste Argentino. De esta manera, es muy probable que el ámbito decorativo del aríbalo sea también un escenario donde se negocian los aspectos culturales locales y foráneos, a propósito de la proliferación de esta forma tecnológica durante el Tawantinsuyu. La recurrencia de esta situación en otros enclaves periféricos del Estado inca, como Santiago del Estero en Argentina, sugiere que el motivo de aspas como elemento local y asociado a las chullpas aymaras están presentes en esta macroárea (Taboada et al. 2013).

Por su parte, los análisis del contenido de algunas vasijas muestran granos de almidón de maíz, sin 
mayor rastro de fermentación; también se encuentran otras especies, como frejol, yuca, pallar y lúcuma. Esta variedad de especies, algunas con señas de trituración, serían indicios de uso de harinas vegetales, evidencia que ha sido relacionada con ritos funerarios de convite con los muertos (Arriaza et al. 2015, 2016, Ogalde 2020).

Este tipo de ritos funerarios en el Collasuyu, denominados "comer y beber con los muertos", tienen referentes arqueológicos (Hastorf 1991, Allen 2002, Arriaza et al. 2015, 2016) y aún hoy se realizan en contextos etnográficos (Van den Berg 1989, Van Kessel 1999, Harris 2005, entre otros). Bartolomé Álvarez (1998 [1588]: 91) escribió tempranamente sobre el área altiplánica aymara del Collasuyu, y señala: "Ofrecen maíz tostado, como si los muertos hubiese de comer [...] Ofrecen asimismo açua que es su bebida, como en otras partes cerveza- [...]". Es importante esta observación sobre los ritos funerarios, pues sugiere que los diversos productos vegetales ofrecidos formaban parte de la producción agrícola local: "Asimismo mochan [ofrecen] las comidas: las papas, la quinoa, la cañua, las ocas, el maíz; en efecto, todas las comidas que por diversas partes se cogen, que cogiéndose en unas partes no se cogen en otra" (Álvarez 1998 [1588]: 85).

Por tanto, la diversidad de plantas observadas podrían ser harinas vegetales de la producción agrícola local que se ofrecían en el ritual fúnebre.

\section{La morfología como semántica y los significados del aríbalo}

Hemos relevado la contraposición de elementos culturales foráneos -relativos a la forma del aríbalo como artefacto- $y$ locales -referentes a la ritualidad fúnebre- que confluyen sobre esta jarra. Estos diferentes complejos culturales, esencialmente simbólicos, podrían estar relacionados con longevas y trabajadas visiones de mundo.

Así, las tres unidades que se requería manufacturar para ensamblar un aríbalo (cuello, cuerpo, base) se plantean como una diferenciación estructural necesaria, vale decir, condición sine qua non en el ensamblaje de la forma aríbalo. Por lo tanto, bien pudiesen representar momentos gnoseológicos que tenían una consideración factual y simbólica. En este sentido, cada subestructura brindaba al aríbalo una serie de ventajas y también diferencias tecnológicas respecto de otras jarras arqueológicas de esta área, atributos que podían ser trabajados de forma selectiva, adaptándolas al ámbito local (i.e. Grupo D).
Luego, la lógica del ensamblaje del aríbalo en tres partes se constituye como producto (fig. 7) en un soporte semántico cosmológico cuyo significado podría corresponderse con la descripción que hace Randall (1993). Este autor sostiene que la chicha se separa en tres niveles semánticos dentro del raki (contenedor): a) el nivel superior, el ñawin, que etimológicamente significa "la parte medular de una cosa", "lo mejor de lo mejor", también es el nombre que se le da a los manantiales de color blanquecino, equivalente al semen masculino como fuerza fertilizante, y se considera como la cosa más propicia para las ofrendas o challa; b) el nivel medio, el aqha es la chicha propiamente tal, que será consumida en la libación. Este espacio está relacionado con el mundo social y cotidiano del individuo; c) el qonchu, nivel inferior, relacionado con el inframundo de los muertos y la vivificación de los manantiales, siendo el sedimento turbio que decanta, comparable a la sangre femenina como fuerza fecundante (Randall 1993, Itier 2013).

El eje basal en cono del aríbalo habría permitido hundir la pieza en el suelo conectando el aqha (chicha de maíz) con la tierra, lo que le asignaba un significado espiritual y cosmogónico a esta relación. Además, pudo funcionar como eje para revolver y mezclar la bebida contenida, lo que permitiría conseguir la espuma o phusuqu. De acuerdo con lo que describe Randall (1993), el phusuqu se vincula al dios Wiraqochan y es muy preciado en los Andes, porque representa el resultado de la procreación, conteniendo la fuerza masculina/fertilidad (ñawin) y femenina/fecundidad (qonchu) unidas en él.

En este sentido, el aríbalo actuó probablemente como uno de los elementos centrales en la celebración de importantes ceremonias religiosas y pagos rituales a las deidades del panteón andino durante el Tawantinsuyu (Randall 1993, Fernández 1995, Bray 2003b, 2012, Dillehay 2003, Cummins 2004). En tanto contenedor de chicha, la forma del aríbalo estuvo posiblemente relacionada con esta visión vertical tripartita del cosmos, la que se resolvía en "lo agrícola" en el Tawantinsuyu. Así, Garcilaso de la Vega (2008 [1609]), quien describe las antiguas prácticas de los tarpuntaes o sacerdotes de la siembra, llama la atención señalando que éstos bebían con los ríos y hacían germinar la tierra. Se creía que "los sacerdotes, al tomar el quonchu después de masticar el maíz, harían fermentar el maíz masticado en sus propios estómagos, lo que sería una manera de estimular el mismo proceso de germinación de los granos de maíz sembrados en la tierra" (Randall 1993: 82). 


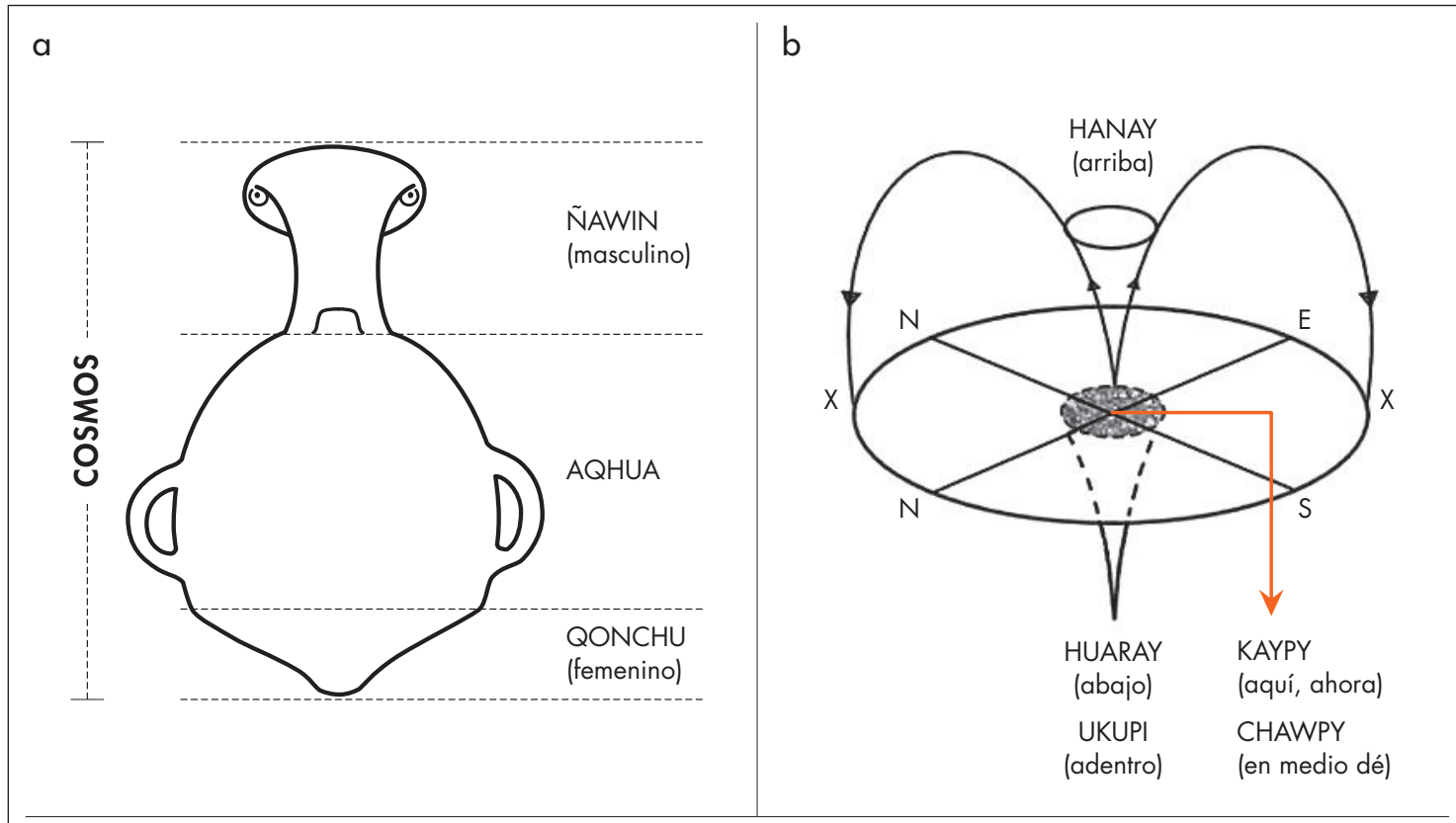

C

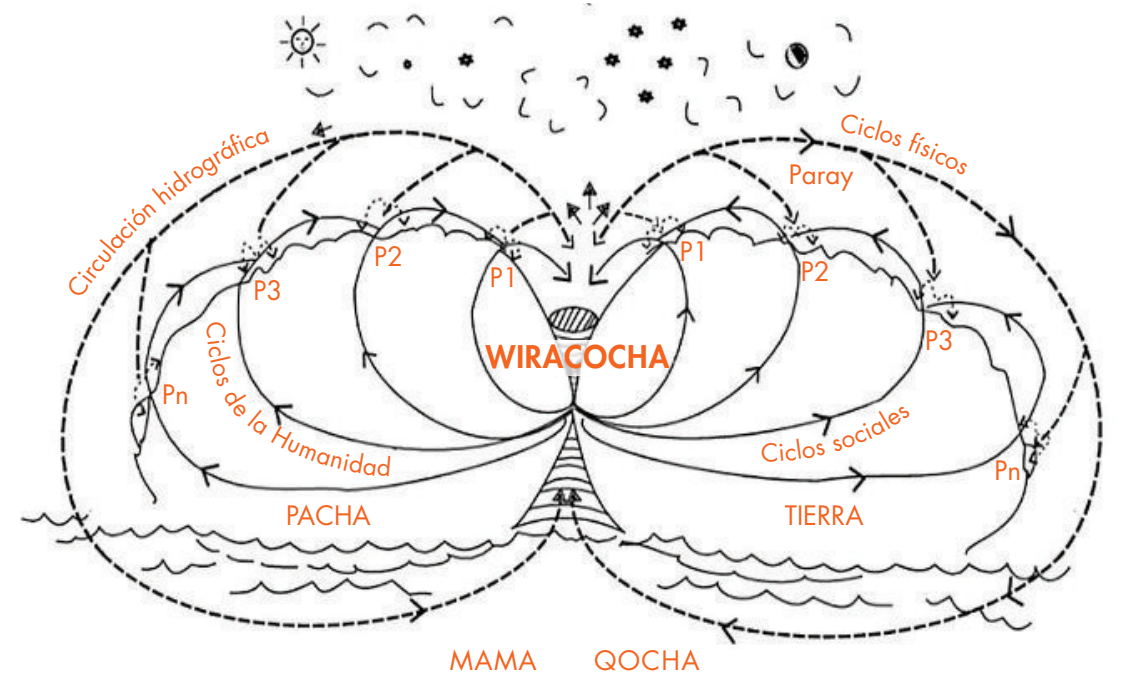

Figura 7: a) adaptación interpretativa del aríbalo según modelo cosmológico del raki propuesto por Randall (1993); b y c) representación de las partes del cosmos según la cosmovisión andina (Earls \& Silverblatt 1978). Figure 7: a) interpretative adaptation of the aryballos according to the Raki cosmological model proposed by Randall (1993); $\boldsymbol{b}$ and $\boldsymbol{c}$ ) representation of the parts of the cosmos according to the Andean cosmovision (Earls \& Silverblatt 1978).

Esta mímesis entre los fenómenos naturales y el cuerpo humano es el aspecto central del nivel $a q h a$, donde el cosmos se hace uno con el sujeto social, quien come y bebe, para luego orinar y defecar, reproduciendo así los ciclos naturales que activan los principios de fertilidad y fecundidad (Randall 1993). En este sentido, el acto de beber o libación se transforma en un elemento importante en sí. Santa Cruz de Pachacuti (1993 [1613]) describe:

Y en este tiempo el dicho ynga despacha a Cacir Capac por vessitador general de las tierras y pastos, dándole su comisión en rayas de palo pintado. Y antes que despacharan esto, ymbía por todo el reyno a Collac Chaguay, curaca de 


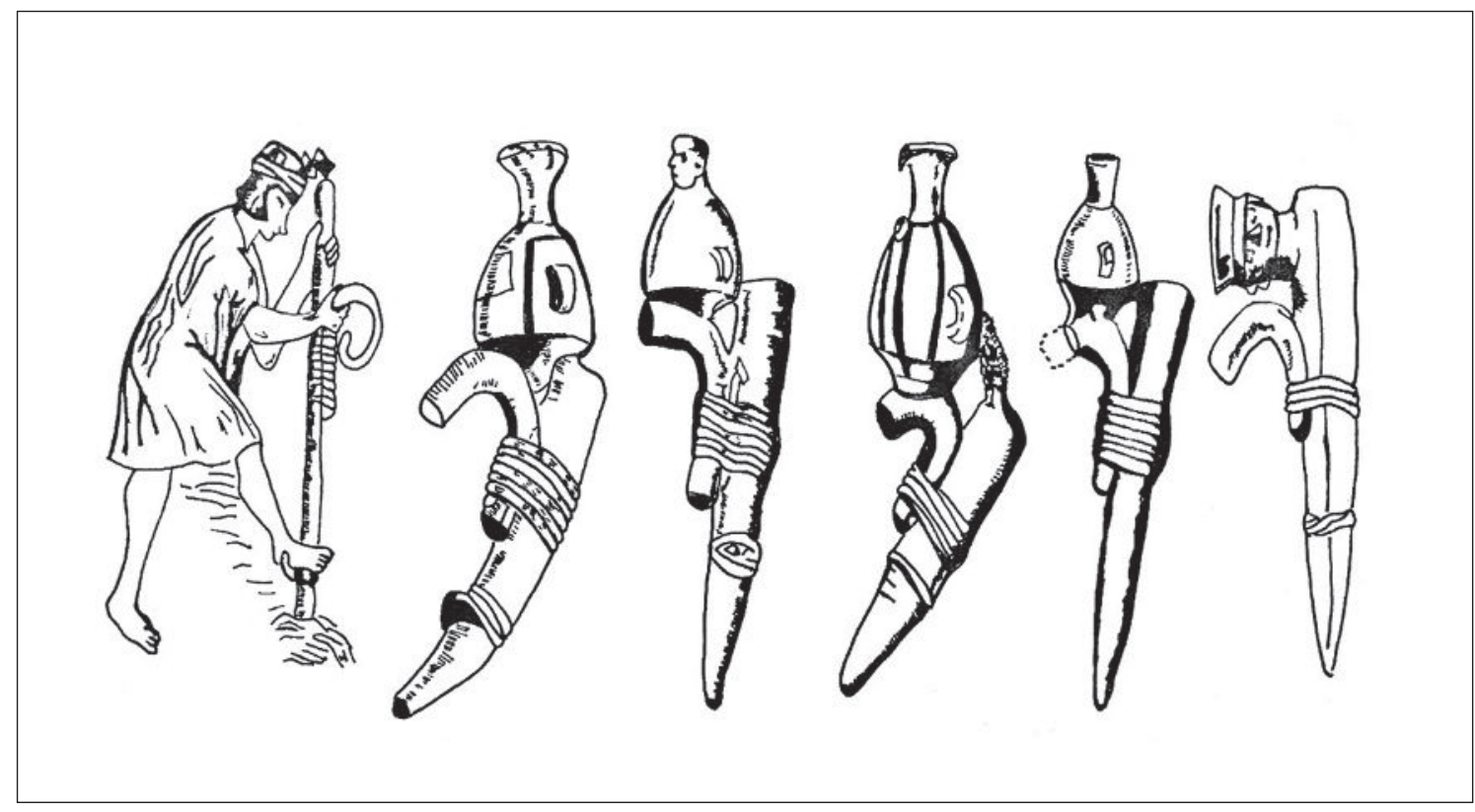

Figura 8. Representaciones de chakitaqllas con aríbalos. (Dibujos: Ribero 2005). Figure 8: Representations of Chakitaqllas (foot plow) with aryballos (Drawings: Ribero 2005).

Tarama de los Chinchaysuyos, para que provasen de comer y bever con todos los curacas, porque este Collac Chauay como era gran comedor y bevedor que Dios abía criado en estas partes. Assí el ynga despacha para dar más chacaras a etc. (Pachacuti en Duviols \& Itier 1993 [1613]: 238).

De los relatos anteriores, se desprende la labor del especialista ritual, del observador oficial y del tragaldabas o gran comedor, todos sujetos oficiantes de la challa en ofrendas a la tierra cultivada, quienes resaltan como grandes bebedores públicos. Todas estas libaciones están relacionadas con la ritualidad y la agricultura. El trabajo de Ribero (2005) sobre los instrumentos asociados a la antigua agricultura en los Andes, permite observar nuevamente la relación del aríbalo con aspectos agrícolas solares, en un conjunto de imágenes de pacchas (recipientes para beber o challar) imitando pequeñas chakitaqllas (instrumentos para labrar) con pequeños aríbalos y cabezas humanas en su parte superior (fig. 8). Estas figuras sugieren un fuerte vínculo entre las representaciones semánticas de los aríbalos y los ciclos naturales que organizan las prácticas agrícolas.

Respecto de los ritos de convite con los muertos, en el norte de Chile -incluyendo el valle de Azapa, el valle de Lluta, el valle de Chaca y el valle de Camarones-, se hicieron análisis del contenido de diversos objetos (incluidos numerosos queros de madera y jarras) de los Períodos Intermedio Tardío (1000-1400 DC) y Tardío u Horizonte Inca (1400-1536 DC). Los resultados mostraron principalmente granos de almidón de maíz y frijol, además de yuca y ají, entre otros, con evidencias de trituración que no parecieran estar relacionadas con los procesos fermentativos del maíz. Es muy probable que estos diversos tipos de harinas vegetales representen la producción agrícola local, pues no hay evidencia de quinua u otro producto típicamente altiplánico, los que sí fueron encontrados en el tártaro dental de los individuos (Arriaza et al. 2015, Ogalde 2020). De hecho, las ofrendas de maíz mezclado con pequeños trozos de carne, o la de cuy o cobaya (Cavia sp.) depositada completa sobre la inhumación en la tumba (FONDECYT 1130261), muestran que, en el valle de Azapa durante el Período Intermedio Tardío y Período Tardío, se realizaban ritos fúnebres que Álvarez describe igualmente para el área altiplánica: "Ofrecen cuyes ["guinea pig”] a las veces sin manchas, blancos, según los elige(n) para tal caso, porque el sacrificio es derramar sangre. Aquellos cuyes no los comen: entiérranlos junto a las sepulturas o dentro" (Álvarez 1998 [1588]: 91).

Una situación similar en el entierro de élite en el cerro Esmeralda en Iquique y en la capacocha de Llu- 
llaillaco en el Noroeste Argentino, sugieren que: a) estos ritos fúnebres eran transversales en esta macroárea y, b) fueron reconocidos por el Inca en tanto formaban parte de estos contextos fúnebres directamente relacionados con el Estado inca. De hecho, se han incorporado en las libaciones estatales del Tawanatinsuyu -que eran específicamente cíclicas y que utilizaban objetos determinados como aríbalos- durante las temporadas relativas a los ritos fúnebres del Collasuyu: "durante el Inti Raymi en junio [...]; durante la siembra en agosto [...]; y por los ritos funerarios (de los inkas) [...] o de los Qollas" (Guaman Poma 1980, en Randall 1993: 75, énfasis del autor).

En el norte de Chile es muy probable que el aríbalo, en tanto vasija para líquidos, se utilizara en ritos fúnebres de convite al muerto, estos serían ancestrales en el área del Collasuyu, remontándose al Horizonte Medio (terminal) en el área del valle de Azapa y en relación con las influencias del Tiwanaku (Ogalde 2020). De esta manera, artefactos prototípicos de las libaciones de las áreas nucleares del Estado inca estarían presentes en las periferias del Tawantinsuyu en su versión mediana (grupos A y B) para ritos fúnebres característicos del Collasuyu, cuyo origen podría contar con el prestigio ancestral de entidades políticas como Tiwanaku.

Nuevamente observamos que, en la forma del aríbalo y en su uso, reposan profundas visiones de mundo que confluyen en la performance social que necesita este artefacto para existir y materializarse. En la medida en que estos artefactos pertenecen al contexto fúnebre, el cual moviliza fuertemente los niveles de significación de la identidad de los individuos sociales -identidades ideales, intencionales, etc.-, estos aspectos, consciente o inconscientemente, fueron negociados en los rituales fúnebres estudiados.

Por ello, se infiere que importantes procesos de la identidad de los individuos eran representados en el contexto fúnebre de los cementerios donde hemos encontrado los aríbalos. La fenomenología asociada a la forma del aríbalo y su uso, como tecnología difundida durante el Tawantinsuyu, sería parte de este contexto funerario del sujeto. Es importante notar que esta jarra es parte de los artefactos propios de cementerios que tienen continuidad con el período cultural anterior, además de otros que emergen durante el Período Tardío, probablemente a propósito de la influencia inca en la macroárea.

Al respecto, los cementerios PLM 4, PLM 6, LLU 13 y LLU 54 tienen continuidad en el Período Intermedio
Tardío, destacando los sitios del valle de Lluta (LLU 13 y LLU 54) que presentan escasos aríbalos, predominando, en cambio, grandes jarrones globulares, como se observa en el ajuar del contexto 15 del cementerio Lluta 54 (fig. 9). Por otro lado, los contextos fúnebres de tradición costera (PLM 4 y PLM 6) muestran indicios de continuidad habitacional desde el Período Intermedio Tardío, donde el sitio PLM 6 presenta ejemplares de aríbalos del Grupo B. Estos ambientes son uniformes entre sí, predominando una variedad de artefactos vinculados con la pesca y la textilería. En el vecino sitio de PLM 4 se observaron aríbalos -entre ellos un ejemplar del Grupo B asociado a artículos de pesca- abundantes y de buen acabado (PLM 4 T106), mientras que, en otro contexto fúnebre (PLM 4 T99), se registró un aríbalo del Grupo B en un ajuar compuesto con materiales de textilería y de pesca.

Paralelamente, durante el Período Tardío surgen otros cementerios, como Az 15 y Chaca 5, cuyos contextos fúnebres emergen en congruencia con la influencia inca en el altiplano boliviano, $o$ anexión del Collasuyu, con artefactos funerarios con evidente influencia altiplánica, la que se articuló con los modos agrícolas de producción de los valles y la pesca en la costa (Santoro et al. 2009; Horta 2013, 2015; Williams et al. 2016). Así, observamos ofrendas funerarias asociadas a numerosos artículos de pesca de buena manufactura (Az 15 T29), además de otros contextos con varios instrumentos musicales $(\mathrm{Az}$ 15 T59) y otros de posibles tejedores (Az 15 T40, T52). Todos ellos acompañados por un aríbalo.

Por otro lado, los ejemplares provenientes de Chaca 5 (T25, T35) son aríbalos de gran tamaño (Grupo C), y muestran rasgos de una manufactura local y aparecen notoriamente acompañados de contenedores de calabazas (a modo de plato o puco). Vale decir, es muy probable que estos cementerios pertenezcan a poblaciones que fueron trasladadas desde el altiplano a estos valles, en calidad de mitimaes de producción. Al respecto, los documentos coloniales más tempranos del área (ca. 1540 Título de Encomienda a Lucas Martínez Begazo) mencionan que las poblaciones de estos valles fueron productores agrícolas de "coca y aji grana", las que serían reclamadas a la postre por caciques del altiplano (Málaga 1981).

Los documentos tempranos del área de Arica muestran una ocupación pluriétnica del valle de Azapa, donde coexistían "Gente de Tarapacá en Arica", "Gente de Tacna en Arica”, "Gente de Ilo en Arica”, "Gente Pacaje 


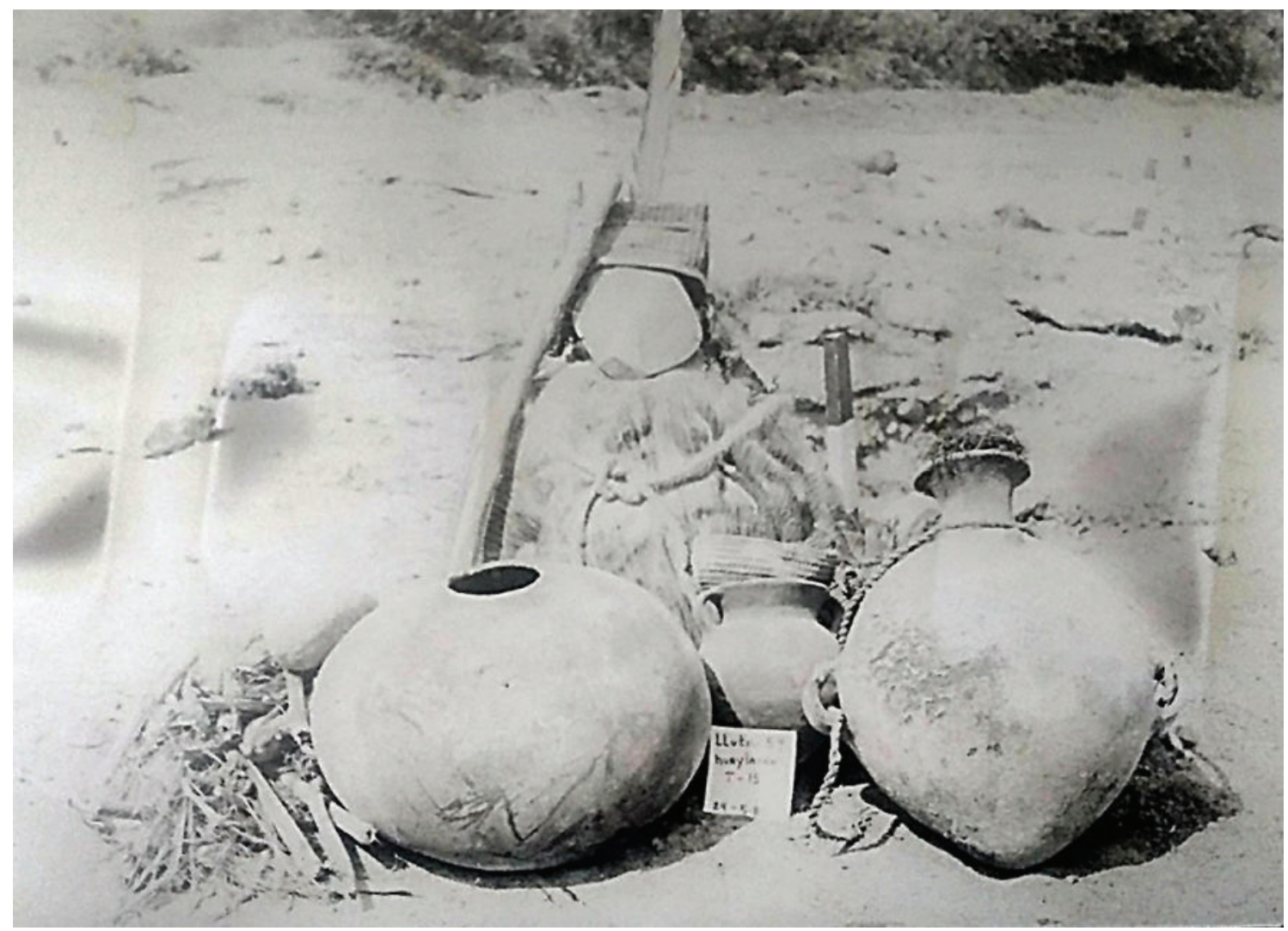

Figura 9. Contexto funerario de élite de Huaylacan, sitio Lluta 54, tumba 15. (Fotografía: gentileza de Juan Chacama). Figure 9: Elite funerary context at Huaylacan, Lluta 54 site, grave 15 (Photograph: courtesy of Juan Chacama).

en Arica", "Gente Yunga y Caranga en Arica" y "Gente Lupaqa en Lluta" (Hidalgo \& Focacci 2004: 418-419). El conjunto de esta evidencia apunta a la diversidad étnica como un motor de la identidad en los momentos coloniales tempranos del área de Arica, que bien pudo ser una manifestación de la ocupación arqueológica temprana de esta área.

\section{CONCLUSIÓN}

Las diferencias en los contextos fúnebres entre la costa y el altiplano en el norte de Chile durante el Período Tardío, con los cementerios de períodos anteriores y contemporáneos a la anexión del Collasuyu al Tawantinsuyu, muestran que el aríbalo negociaba entre elementos culturales foráneos y transversales -como la proliferación de su forma- y elementos locales -como ritos fúnebres-, dinamizando los aspectos biográficos que marcan parte de la identidad multiétnica presente en el área. Así, mediatizados por la realidad del altiplano circuntiticaca, en los contextos fúnebres del norte de Chile el aríbalo contiene a la vez, en esencia, dos mundos ancestrales y diferentes. El axis mundis de la ideología del Estado inca, materializada en el quechua, en relación con la preparación de la chicha (Randall 1993), y aquel ancestral convite a los muertos, que formaría parte de la herencia escatológica Tiwanaku en esta macroárea (Ogalde 2020).

Por extrapolación y abducción de objetos con agencia como el aríbalo, estos aspectos debiesen estar relacionados con la identidad del individuo social en la medida en que son parte de los contextos fúnebres. En este punto, es posible afirmar que estos dos mundos que se están negociando serían parte del acervo cultural del individuo empírico, con grados parciales de protagonismo en los procesos de identidad del sujeto fúnebre, donde se materializa este conocimiento. Sin 
embargo, la construcción social de la identidad de estos sujetos determinó que estos dos mundos -entrevistos en el aríbalo- formaran parte de la identidad ideal de estas personas.

Agradecimientos Al proyecto Fondecyt $\mathrm{N}^{\circ} 1130261$, que nos permitió realizar este estudio. Asimismo, agradecemos especialmente a Deposito Arqueológico de Calama, Juan Chacama, a Ninoska Cisterna y al Taller de Cerámica Artística de la Universidad de Tarapacá.

\section{REFERENCIAS}

Agrawal, A. 2005. Environmentality. Technologies of government and the making of subjects. Durham: Duke University Press.

AlBó, X. 1991. Rostros indios de Dios. Quito: Abya-Yala.

Allen, C. 2002. The hold life has: coca and cultural identity in an andean community. Washington DC: Smithsonian Books.

Althusser, L. 1988. Ideología y aparatos ideológicos del Estado. Buenos Aires: Freud y Lacan, Nueva Visión.

Álvarez, B. 1998 [1588]. De las costumbres y conversión de los indios del Perú. Memorial a Felipe II. Madrid: Polifemo.

Amuedo, C. 2015. Las vasijas y su potencial como sujetos estabilizadores de seres incompletos: prácticas mortuorias de infantes durante el Período Tardío en el valle Calchaquí Norte. Estudios Atacameños 50: 85-104.

Arriaza, B., Ogalde, J., Chacama, J., Standen, V., Huamán, L. \& Villanueva, F. 2015. Estudio de almidones en queros de madera del norte de Chile relacionados con el consumo de chicha durante el Horizonte Inca (1470-1530 DC). Estudios Atacameños 50: 59-84.

Arriaza, B., Ogalde, J., Chacama, J., Standen, V., Huaman, L., Villanueva, F., Aravena, N., Méndez-Quiros, P. \& TAPIA, P. 2016. Microscopic analysis of botanical residues from Cerro Esmeralda burial in northern Chile: state and death ritual implications. Interciencia 41 (12): 844-850.

Arriaza, B., Ogalde, J. P., Campos, M., Paipa, C., Leyton, P. \& LARA, N. 2018. Toxic pigment in a capacocha burial: instrumental identification of cinnabar in inca human remains of Iquique, Chile. Archaeometry 60 (1): 1324-1333.

Besom, T. 2000. Mummies, mountains, and immolations: strategies for unifying the Inka Empire's southern quarters. Tesis para optar al grado de Doctor en Antropología, Universidad de Binghamton, Nueva York.

Besom, T. 2013. Inca human sacrifice and mountain worship. Strategies for empire unification. Albuquerque: University of New Mexico Press.

BRAY, T. 2003a. Inka pottery as culinary equipment: food, feasting, and gender in imperial state design. Latin American Antiquity 14 (1): 3-28.

BRAY, T. 2003b. To dine splendidly: imperial pottery, commensal politics and de Inca State. En The archaeology and politics of food and feasting in early states and empires, T. Bray,
Ed., pp. 93-142. Nueva York: Kluwer Academic-Plenum Publishers.

BRAY, T. 2004. La alfarería imperial inka: una comparación entre la cerámica estatal del área de Cuzco y la cerámica de las provincias. Chungara 36: 365-374.

BRAY, T. 2009. The rol of chicha in Inka state expansion: a distributional study of inka aríbalos. En Drink, power, and society in the Andes, J. Jennings \& B. Bowser, Eds., pp. 108-132. Gainesville: University Press of Florida.

BraY, T. 2012. Ritual commensality between human and non-human persons: investigating native ontologies in the late pre-columbian andean world. Journal for Ancients Studies 2: 197-212.

Ceruti, M. 2003. Llullaillaco. Sacrificios y ofrendas en un santuario inca de alta montaña. Salta: Universidad Católica de Salta.

Checura, J. 1977. Funebria incaica en el cerro Esmeralda (Iquique, I Región). Estudios Atacameños 5: 127-144.

Cisterna, N. 2015. Caracterización de patrones iconográficos en vasos quero y aríbalos del Período Tardío. Una aproximación iconográfica en el extremo norte de Chile. Tesis para optar al grado de Arqueóloga. Departamento de Antropología, Facultad de Ciencias Sociales y Jurídicas, Universidad de Tarapacá.

Cummins, T. 2004. Brindis con el Inca. La abstracción andina y las imágenes coloniales de los queros. Perú: Universidad Nacional Mayor de San Marcos.

D’Altroy, T., Lorandi, A. \& Williams, V. 1994. Producción y uso de la cerámica en la economía política inca. Arqueología 4: 73-172.

De Santa Cruz Pachacuti, J. 1993 [1613]. Relación de antigüedades deste reyno del Piru. En Relación de antigüedades deste reyno del Piru. Estudio etnohistórico y lingüístico, P. Duviols \& C. Itier, Eds., pp. 179-268. Lima: Instituto Francés de Estudios Andinos-Centro Bartolomé de Las Casas.

DietLer, M. 2006. Alcohol: anthropological/archaeological perspectives. Annual review of Anthropology 35: 229-249.

Dillehay, T. 2003. El colonialismo inka, el consumo de chicha y los festines desde una perspectiva de banquetes políticos. Boletín de Arqueología PUCP 7: 355-363.

Dobres, M. 2010. Archaeologies of technology. Cambridge Journal of Economics 34 (1): 103-114.

EARLS, J. \& Silverblatt, I. 1978. La realidad física y social en la cosmología andina. En Actes du XLII Congrès International des Américanistes 1976, B. Albert, Ed., pp. 443-473 París.

FERnÁndeZ, G. 1995. El banquete aymara: mesas y yatiris. La Paz: Isbol.

FocACCI, G. 1981. Descripción de un cementerio incaico en el valle de Azapa. Chungara 3: 23-74.

Foucault, M. 2010. Vigilar y castigar. Nacimiento de la prisión. Madrid: Siglo XxI.

Galvin, S. 2004 [1590]. Códice Murúa, historia y genealogía, de los reyes incas del Perú del padre americano Fray Martín de Murúa. España: Testimonio. 
Garcilaso De la Vega, I. 2008 [1609]. Comentarios reales de los incas. Lima: A.F.A.

Gell, A. 2016. Arte y agencia. Una teoría antropológica. Argentina: $\mathrm{Sb}$.

Goldstein, P. 2003. From stew-eaters to maize-drinkers: the chicha economy and the Tiwanaku expansión. En The archaeology and politics of food and feasting in early states and empires, T. Bray, Ed., pp. 143-172. Nueva York: Kluwer Academic, Plenum Publishers.

Guaman Poma De Ayala, F. 1615. Nueva corónica y buen gobierno. <http://www.kb.dk/permalink/2006/poma/8/ es/text/?open=id3083606 $>$ [consultado: 10-08-2013].

Hall, S. 1995. Negotiating caribbean identities. New Left Review 209: 3-14.

Han, B. 2019. Psicopolítica. Barcelona: Herder.

HarawaY, D. 1991. Simians, cyborgs, and women: the reinvention of nature. Nueva York: Routledge.

HARRIS, M. 2005. Riding a wave: embodied skills and colonial history on the amazon floodplain. Ethnos 70 (2): 197-219.

Hastorf, C. A. 1991. Gender, space and food in prehistory. En Engendering archaeology: women and prehistory, J. Gero \& M. W. Conkey, Eds., pp. 132-159. Oxford: Blackwell.

HAYASHIDA, F. 1998. New insights into inka pottery production. En Andean ceramics: technology, organization, and approaches, I. Shimada, Ed., pp. 313-335. Filadelfia: Museum of Archaeology and Anthropology, University of Pennsylvania.

Hayashida, F. 2008. Ancient beer and modern brewers: ethnoarchaeological observations of chicha production in two regions of the north coast of Peru. Journal of Anthropological Archaeology 27: 161-174.

Hidalgo, J. \& Focacci, G. 2004. Multietnicidad en Arica, siglo XVI. Evidencias etnohistóricas y arqueológicas. En Historia andina en Chile, J. Hidalgo, Ed., pp. 417-429. Santiago: Universitaria.

Horta, H. 2013. Queros de madera del Collasuyo: nuevos datos arqueológicos para definir tradiciones (s. XIV-XVI). Estudios Atacameños 45: 95-116.

Horta, H. 2015. El señorío Arica y los reinos altiplánicos (1000-1540 DC). Complementariedad ecológica y multietnicidad durante los siglos pre-conquista en el norte de Chile. Coquimbo: Qillqa.

INGOLD, T. 2008. Materials against materiality. Archaeological Dialogues 14 (1): 1-38.

ITIER, C. 2013. Viracocha o el océano, naturaleza y funciones de una divinidad andina. Lima: Institut Français d'Etudes Andines-Instituto de Estudios Peruanos.

Kesseli, R. \& PÄrssinen, M. 2005. Identidad étnica y muerte: torres funerarias (chullpas) como símbolos de poder étnico en el altiplano boliviano de Pakasa (1250-1600 DC). Boletín del Instituto Francés de Estudios Andinos 34 (3): 379-410.

Latour, B. 1999. Pandora's hope: essays on the reality of science studies. Cambridge: Harvard University Press.

LATOuR, B. 2008. Reensamblar lo social. Una introducción a la teoría de actor-red. Buenos Aires: Manantial.
LeChtman, H. 1977. Style in technology: some early thoughts. In Material culture: styles, organization, and dynamics, $\mathrm{H}$. Lechtman \& R. Merril, Eds., pp. 3-20. Minnesota: West Publishing.

LI, T. 2000. Articulating indigenous identity in Indonesia: resource politics and the tribal slot. Comparative Studies in Society and History 42 (1): 149-79.

Martinon-Torres, M. \& Killick, D. 2016. Archaeological theories and archaeological sciences. En The Oxford handbook of archaeological theory, A. Gardner, M. Lake \& U. Sommer, Eds., pp. 1-17. Oxford: Oxford University Press.

Málaga, A. 1981. Arequipa, estudios históricos. Arequipa: Biblioteca Arequipa.

Meyers, A. 1975. Algunos problemas en la clasificación del estilo incaico. Pumapunku 8: 7-25.

Morris, C. 1995. Symbols to power: styles and media in the Inka State. En Style, society and person. Archaeological and ethnological perspective, C. Carr \& J. Neitzel, Eds., pp. 419-433. Nueva York: Plenum Press.

Murra, J. 1978. La organización económica del Estado Inca. México: Siglo XXI.

Núñez, L., Niemeyer, H. \& Falabella, F. (Eds.) 1994. La cordillera de los Andes: ruta de encuentros. Santiago: Museo Chileno de Arte Precolombino.

Ogalde, J. P. 2020. Sobre el origen cultural del quero Cabuza. Los grupos sociales detrás de su tecnología de producción y uso. Tesis para optar al grado de doctor en Arqueología. Departamento de Antropología. Facultad de Ciencias Sociales y Jurídicas, Universidad de Tarapacá.

PANofsky, E. 2004. Estudios sobre iconología. Madrid: Alianza.

PÄRssinen, M. 2002. Confederaciones interprovinciales y grandes señores interétnicos en el Tawantinsuyu. Boletín Arqueología PUCP 6: 23-41.

Piazza, F. 1981 Análisis descriptivo de una aldea incaica en el sector Pampa Alto Ramírez. Chungara 7: 172-216.

RANDALl, R. 1993. Los dos vasos. Cosmovisión y política de la embriaguez desde el Inkanato hasta la Colonia. En Borrachera y memoria. La experiencia de lo sagrado en los Andes, T. Saignes, Ed., pp. 73-112. La Paz: Hisbol-Instituto Francés de Estudios Andinos.

Reinhard, J. \& Ceruti, M. C. 2005. Pilgrimage, sacred mountains, and human sacrifice among the Inca. En Pilgrimages and ritual landscape in pre-columbian America, J. Carlson, Ed., pp. 215-233. Washington DC: Dumbarton Oaks.

Ribero, V. 2005. Herramientas agrícolas del Perú antiguo. Cusco: Centro Bartolomé de Las Casas.

Rовв, J. 2008. Tradition and agency: human body representations in later prehistoric Europe. World Archaeology 40: 332-53.

Rовв, J. 2010. Beyond agency. World Archaeology 42 (4): 493-520. Rosberry, W. 2002. Hegemonía y el lenguaje de la contienda. En Everyday forms of state formation. Revolution and the negotiation of rule in modern Mexico, J. Gilbert \& D. Nugent, Eds., pp. 355-366. Durham: Duke University Press. 
Rostworowski, M. 2014. Historia del Tahuantinsuyu. Lima: Instituto de Estudios Peruanos.

Rowe, J. 1944. An introduction to the archaeology of Cuzco. Cambridge: Peabody Museum of Archaeology.

Rowe, J. 1961. The chronology of inca wooden cups. En Essays in precolumbian art and archaeology, S. Lothrop, Ed., pp. 317-341. Cambridge: Harvard University Press.

SAntoro, C. \& MuÑoz, I. 1981. Patrón habitacional incaico en el área de Pampa Alto Ramírez (Arica, Chile). Chungara 7: 144-171.

Santoro, C., Romero, A., Standen, V. \& Valenzuela, D. 2009. Interacción social en los Períodos Intermedio Tardío y Tardío, valle de Lluta, norte de Chile. En La arqueología y la etnohistoria. Un encuentro andino, J. Topic, Ed., pp. 81-137. Lima: IEP-IAR.

Sillar, B. 2009. The social agency of things? Animism and materiality in the Andes. Cambridge Archaeological Journal 19 (3): 367-377.

Silliman, S. 2001. Agency, practical politics and the archaeology of the culture contact. Journal of Social Archaeology 1 (2): 190-209.

SMith, A. 2001. The limitations of Doxa: agency and subjectivity from an archaeological point of view. Journal of Social Archaeology 1 (2): 155-171.
Taboada, C., Angiorama, C., Leiton, D. \& López, S. 2013. En la llanura y en los valles... Relaciones entre las poblaciones de las tierras bajas santiagueñas y el Estado Inca. Inserciones en Antropología 14: 137-156.

Thomas, H. \& Buch, A. (Comp.) 2013. Actos, actores y artefactos: sociología de la tecnología. Buenos Aires: Universidad Nacional de Quilmes.

VAn Den Berg, H. 1989. La celebración de los difuntos entre los campesinos aymaras del Altiplano. Anthropos 84: 155-175.

VAn Kessel, J. (Ed.) 1999. Los vivos y los muertos, duelo y ritual mortuorio en los Andes. Iquique: IECTA.

Villanueva, J. 2014. Yachay, pacha, tinku. La mutua constitución de la persona y los ceramios en el Período Intermedio Tardío (ap. 1100-1450 DC) del altiplano central de Bolivia. Un ejercicio de aplicación. En Personas, cosas, relaciones. Reflexiones arqueológicas sobre las materialidades pasadas $y$ presentes, F. Acuto \& V. Franco, Eds., pp. 117-150. Quito: Abya-Yala.

Williams, V., Santoro, C., Speakman, R., Glascock, M., Romero, Á., Valenzuela, D., Standen, V. \& D’Altroy, T. 2016. Instrumental neutron activation analysis of Inka and local pottery from northern Chile's Atacama Desert. Journal of Archaeological Science Reports 9: 481-492.

WINNER, L. 1977. Autonomous technology: technics out of control as a theme in political thought. Cambridge: Miт Press. 